\title{
Difference of Height, Body Mass Index and Self-Assessment Among High-School Students in Constanta County-a comparison between rural and urban areas.
}

Ovidius University of Constanta, Faculty of Medicine

\begin{abstract}
The increasing prevalence of obesity among highschool students is a public health problem, as more and more children are facing it.[5] Education has a great impact on the way young people deal with this problem. A significant effect on the behaviour of the pupils is the background they have, differences between children from rural areas compared to children from urban areas in terms of BMI being documented.

A number of 185 high-school students from two schools in Constanta, from urban and rural areas were interviewed and data about height and weight was collected.

The results show that there is no statistically significant difference of the height between teenagers from urban and rural area, but there is a statistically significant association between area and BMI-z score distribution. Also, a higher number of teenagers from urban area underestimate their weight status compared to teenagers from rural areas.
\end{abstract}

Keywords: Adolescent, Body Height, Body Mass Index, Urban, Rural

\section{Sergiu Chirilă}

Faculty of Medicine, Ovidius University of Constanta

1st Aleea Universitati, camp B,

Constanta, Romania

sergiu.chirila@yahoo.com

$+40721332068$

\section{Introduction}

The increasing prevalence of obesity among high-school students is a public health problem, as more and more children are facing it.[5] Education has a great impact on the way young people deal with this problem. A significant effect on the behaviour of the pupils is the background they have, differences between children from rural areas compared to children from urban areas in terms of BMI being well documented. This has an effect through different ways: education, activity level, self-esteem, habits related to eating etc.

Obesity represents a problem not only for the adolescent, but it has a direct effect on the health status of the adult [2], thus increasing the burden of the metabolic diseases, psychological problems, social problems etc.

The main reason for the increasing prevalence of overweight and obesity in adolescents is the consequence of increased energetic input (high caloric density products) and decreased adherence to physical activity.[10]

The purpose of the study is to identify and compare the overweight and obesity prevalence 
among high-school students in Constanta County in rural and urban areas schools, and to compare the way they deal and perceive their situation.

\section{Material and Method}

For this study we conducted an interview in two schools from Constanta County, one situated in a rural area (students with rural background) and one from an urban area (students from urban areas). The questionnaire was applied to a total number of 185 pupils, 83 with urban background and 102 with rural background. Pupils were of different levels (from 9th to 12 th grade $-14-18$ years old).

There was a statistically significant disproportion $(p<0.001)$ between urban and rural area of the distribution according to sex (Table 1). In the urban area the percentage of girls in our study was higher than in the rural area. This is corrected by using z-scores (for BMI and height), scores that are adjusted according to sex and age.

Measurements for the height and weight were done with proper instruments, in the school's medical office, under the supervision of a qualified person.

The questionnaire applied was Youth Risk Behaviour Surveillance System designed for highschool level pupils. For this study we considered only the questions relevant to the topic in discussion.

For each student, Body Mass Index (BMI) was calculated based on the data about height and weight. We calculated the BMI-z scores for each student, according to age and sex based on the WHO child growth reference 5-19 years[11]. Interpretation of the results was made also according to WHO cut-offs based on standard deviations (Table 1):

Table 1 Cut-offs BMI-z score for children 5-19 years old

\begin{tabular}{|l|c|}
\hline Overweight: & $>+1 \mathrm{SD}$ \\
\hline Obesity & $>+2 \mathrm{SD}$ \\
\hline Thinness & $<-2 \mathrm{SD}$ \\
\hline Severe thinness & $<-3 \mathrm{SD}$ \\
\hline
\end{tabular}

Also, for height, adjusted values were used (height-for-age), according to WHO child growth reference 5-19 years. For weight-for-age data was not standardized as it is inadequate for monitoring growth beyond childhood due to its inability to distinguish between relative height and body mass.[12]

Cases where the data was incomplete were excluded from the analysis of the specific topic. Also, a test to exclude outliers was conducted. The result was that there were no abnormal values.

Data was collected in an electronic database and was interpreted with the help of computer based statistical programs. To determine the statistical significance of observed differences, the $t$ test was used in case of normal distributed values, the MannWhitney $U$ test in case the distribution was different from a normal one, in case of continuous variables. The association level was measured with the help of the Chi-square test. If conditions for Chi-square test were not to be met, the Likelihood Ratio was used instead. The threshold for statistical significance was considered to be $\leq 0.05$.

\section{Results}

\section{Height}

The average height for the pupils in urban area was $166.7 \mathrm{~cm}( \pm 7.09 \mathrm{~cm})$, while for the rural area the average height was $169.78 \mathrm{~cm}( \pm 8.25 \mathrm{~cm})$ (Table 2 ). The difference is statistically significant; after applying the $\mathrm{t}$ test, the $\mathrm{p}$ value was 0.009 .

Table 2 Mean values for height

Group Statistics

\begin{tabular}{l|lllll}
\hline & Background N & Mean & $\begin{array}{l}\text { Std. } \\
\text { Deviation }\end{array}$ & $\begin{array}{l}\text { Std. Error } \\
\text { Mean }\end{array}$ \\
\hline \multirow{2}{*}{ Height (cm) } & Urban & 79 & 166.70 & 7.095 & .79824 \\
& Rural & 100 & 169.78 & 8.254 & .82543 \\
\hline \hline
\end{tabular}


Because the sample of students differs significantly when it comes to sex ratios, this comparison might not be very relevant to discuss differences according to background. Therefore, to compare the height of the students, standardization according to sex and age was necessary. For that, we used growth charts references from WHO. In Table 3 the average SD is calculated for pupils in urban and rural areas. For urban areas, the mean SD is 0.36 ( \pm 0.847$)$, while for rural area it is $0.47( \pm 0.848)$.

Table 3 Mean height SD values for pupils in Urban and Rural areas

\begin{tabular}{lll}
\hline \hline Background & & Height/Age SD \\
\hline \multirow{3}{*}{ Urban } & Mean & .3632 \\
& $\mathrm{~N}$ & 79 \\
& Std. Deviation & .84766 \\
& Mean & .4717 \\
Rural & $\mathrm{N}$ & 99 \\
& Std. Deviation & .84809 \\
& Mean & .4235 \\
Total & $\mathrm{N}$ & 178 \\
& Std. Deviation & .84723 \\
\hline \hline
\end{tabular}

Analysing the height-for-age $\mathrm{z}$ score, we see that there are no shorter than normal (less than -2 SD) pupils in the urban area, while for the rural area only $1 \%$ of the adolescents are below the standard height for age.

Higher than normal $(+1 \mathrm{SD})$ there are $22.8 \%$ of the pupils in urban area compared to $26.3 \%$ in rural areas. A deviation of more than $+2 \mathrm{SD}$ is seen in $5.1 \%$ of the cases in urban areas and 3\% in rural areas (Figure 1).

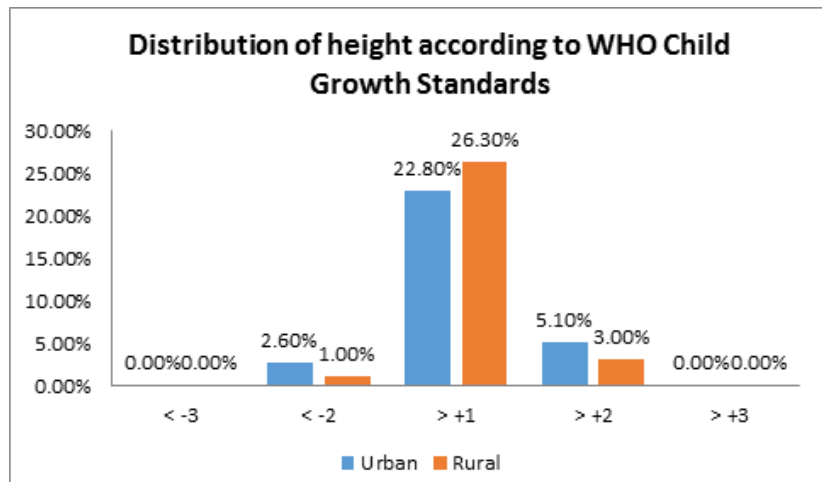

Figure 1 Distribution of height according to WHO Child Growth Standards

There is no significant association between the area of the adolescents and the distribution according to height (exact $\mathrm{p}=0.795$ ).

\section{Body Mass Index}

For BMI-z score, we see (Table 4) that the average SD for high school students in the urban area is $-0.05( \pm 1.17)$, while for the high school students in the rural area it is $-0.2( \pm 0.95)$. The mean values show that, on average, pupils in both areas are very close to a normal BMI-for-age, with slightly lower values for the pupils in rural areas.

Table 4 Mean BMI-z SD values for pupils in Urban and Rural areas

\begin{tabular}{lll}
\hline \hline Background & & BMI/Age SD \\
\hline \multirow{4}{*}{ Urban } & Mean & -.0538 \\
& $\mathrm{~N}$ & 78 \\
& Std. Deviation & 1.17323 \\
& Mean & -.2016 \\
Rural & $\mathrm{N}$ & 96 \\
& $\mathrm{Std}$. Deviation & .94884 \\
& Mean & -.1353 \\
Total & $\mathrm{N}$ & 174 \\
& Std. Deviation & 1.05473 \\
\hline \hline
\end{tabular}


Analysing the BMI-z scores, the data shows that more than one in every four high school students from urban area are overweight or obese, while in the rural area one in ten high school students are overweight or obese.

In order to determine if there are significant differences between the two backgrounds, pupils where assigned to three categories: underweight (BMI-z <-2 and lower), normal weight (BMI-z between -1 and +1 ), overweight and obese (BMI-z $>+1$ and larger). (Table 5, FIgure 2)

Table 5 Development according to BMI-z score

\begin{tabular}{|c|c|c|c|c|c|}
\hline & & \multicolumn{3}{|l|}{ Status } & \multirow[t]{2}{*}{ Total } \\
\hline & & Underweight & $\begin{array}{l}\text { Normal } \\
\text { weight }\end{array}$ & $\begin{array}{l}\text { Overweight } \\
\text { and Obese }\end{array}$ & \\
\hline \multirow{2}{*}{ Background } & Urban & 2 & 56 & 20 & 78 \\
\hline & Rural & 1 & 85 & 10 & 96 \\
\hline Total & & 3 & 141 & 30 & 174 \\
\hline
\end{tabular}

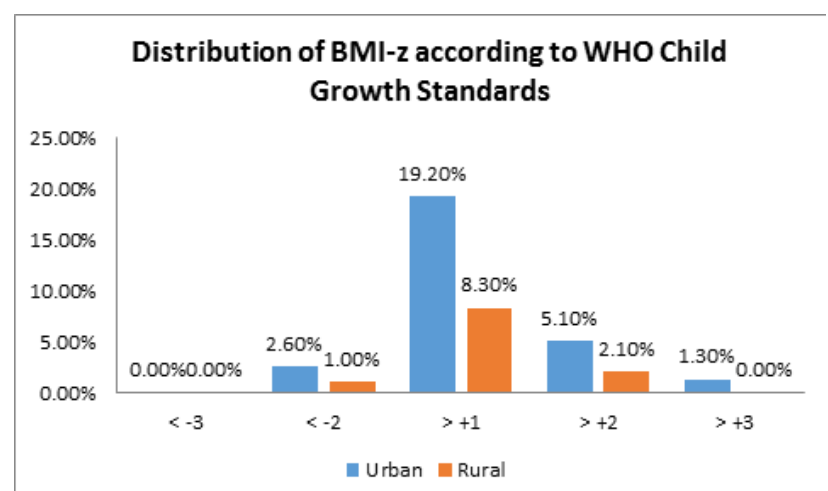

Figure 2 Distribution of BMI-z according to WHO Child Growth Standards

A Chi-square test was conducted, but more than $20 \%$ of the expected values were less than 5 , so we considered the Likelihood Ratio test. This test returned an exact $p$ value of 0.018 . (Table 6) The conclusion is that the background has a determinant effect on the BMI-z score of the high school students.
Table 6 Chi-square and Likelihood Ratio test

Chi-Square Tests

\begin{tabular}{lllll}
\hline \hline & Value & df & $\begin{array}{c}\text { Asymp. Sig.Exact } \\
\text { (2-sided) }\end{array}$ & Sig. \\
& & & (2-sided) \\
\hline Pearson Chi-Square & $7.853^{\mathrm{a}}$ & 2 & .020 & .011 \\
Likelihood Ratio & 7.880 & 2 & .019 & .018 \\
Fisher's Exact Test & 7.843 & & & .009 \\
N of Valid Cases & 174 & & &
\end{tabular}

a. 2 cells $(33.3 \%)$ have expected count less than 5 . The minimum expected count is 1.34 .

To calculate the size of the effect, we used Cramer's V test. This returned a value of 0.212 , with an exact $\mathrm{p}=0.011$.

\section{Self-assessment}

Another important part of this study was to assess the way adolescents perceive their body weight. For that they were asked "How do you describe your weight?". Possible answers were:

1. Very underweight

2. Slightly underweight

3. About the right weight

4. Slightly overweight

5. Very overweight

We compared the results we obtained through objective assessment (measurements) and the results from the answers of the pupils for each background. For a better comparison, BMI-z scores of $>+2$ and $>+3$ were summed up to correspond to the answer "Very overweight".

For high school students in urban area the results show that they have a good evaluation of their body weight, especially for the ones that are overweight or obese (4 and 5 in Figure 3). At the same time, 18.1\% of the students say that they are slightly or very underweight, while, according to the measurements, only $2.6 \%$ could be categorised as being underweight and none of them very underweight. 


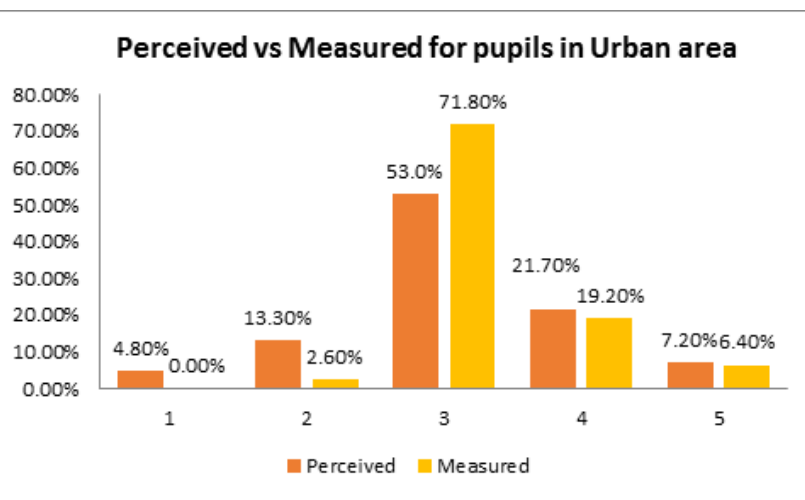

Figure 3 Perceived vs Measured for pupils in Urban area

For high school students in rural area the results show that the approximation they gave for being overweight or very overweight is different from the actual results, a larger percentage of students considering that they have a weight above normal than the actual number (Figure 4, Categories 4 and 5). At the same time, almost $10 \%$ of the pupils consider that they are underweight or very underweight, while, according to the measurements done, only $1 \%$ of the students have a BMI-z score that classifies them into the underweight category.

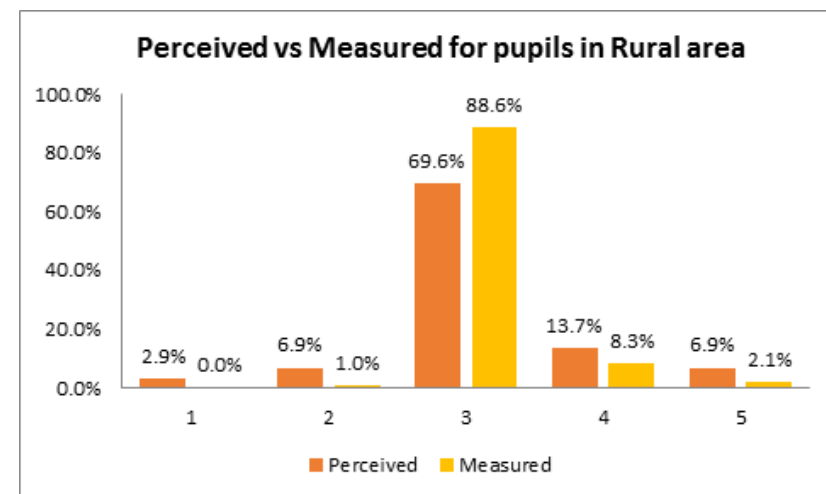

Figure 4 Perceived vs Measured for pupils in Rural area

\section{Discussions}

We didn't observe a clear association between background and height-for-age in our study. Data regarding this subject is debatable and probably is influenced by the socio-economic and cultural factors. Studies conducted in different areas show different results, with an accentuated difference especially in lower developed countries $[3 ; 6 ; 8]$ and a less evident difference in developed countries.

For BMI we concluded that there are significant differences between adolescents in urban and rural areas, with a higher percentage of overweight and obese adolescents in urban areas $(25.6 \%)$ compared to the ones in rural areas (10.4\%). This is a result which is consistent with the results found in specialized literature. The feeding habits seem to have a minimal impact, several studies, conducted in countries with a similar development showing that even though there were differences of the BMI between urban and rural areas adolescents, feeding habits were similar [4]. Probably this difference is caused especially by the habits related to physical activity (teenagers in urban areas tend to have a more sedentary lifestyle) [7].

The present findings suggest that a significant percentage of adolescents do not assess their weight status correctly. Almost $20 \%$ of the adolescents in urban areas consider that their weight is below normal weight. Monitoring the way teenagers perceive their weight status is necessary. In our study the underestimation was more frequent, especially in the urban area group. This might be a real issue, especially if underestimation comes from teenagers that are overweight, thus reducing the motivation to lose weight [1]. This was the case for almost $20 \%$ of the adolescents in urban areas and only $10 \%$ for the ones in rural areas. Overestimation, which was more frequent in the rural area, represents a real risk for unhealthy interventions for weight control.[9] 
High school students in rural areas have a statistically significantly higher chance of having a normal BMI-for-age compared to high school students in urban areas.

The percentage of overweight and obese students in urban areas is statistically significantly higher compared to the high school students in rural areas.

High school students from urban areas recognise with high accuracy the overweight and obese status, while high school students in rural areas tend to overestimate their weight. At the same time, adolescents from urban areas have a higher tendency to underestimate their body weight in a larger proportion than the ones in rural areas.

No statistically significant difference according to height-for-age was observed between urban and rural areas.

\section{References}

1. Brug, J., Wammes, B., Kremers, S., Giskes, K., \& Oenema, A. (2006). Underestimation and overestimation of personal weight status: associations with socio-demographic characteristics and weight maintenance intentions. J Hum Nutr Diet, 19(4), 253-262. doi: 10.1111/j.1365-277X.2006.00707.x

2. Dietz, W. H. (1998). Health consequences of obesity in youth: childhood predictors of adult disease. Pediatrics, 101(3 Pt 2), 518-525.

3. Fox, K., \& Heaton, T. B. (2012). Child nutritional status by rural/urban residence: a cross-national analysis. J Rural Health, 28(4), 380-391. doi: 10.1111/j.1748-0361.2012.00408.x

4. Hoffmann, K., Bryl, W., Marcinkowski, J. T., Rzesos, A., Wojtyla, E., \& Pupek-Musialik, D. (2012). Dietary behaviours of adolescents from urban and rural areas in the district of Szamotuly-a preliminary study. Ann Agric Environ Med, 19(1), 103-107.

5. Kopelman, P. G., Caterson, I. D., \& Dietz, W. H.
(2010). Clinical obesity in adults and children (3rd ed.). Chichester, West Sussex ; Hoboken, N. J.: Wiley-Blackwell.

6. Luo, Y., Yang, F., Lei, S. F., Wang, X. L., Papasian, C. J., \& Deng, H. W. (2009). Differences of height and body mass index of youths in urban vs rural areas in Hunan province of China. Ann Hum Biol, 36(6), 750-755. doi: 10.3109/03014460903120925

7. Machado-Rodrigues, A. M., Coelho, E. S. M. J., Mota, J., Padez, C., Martins, R. A., Cumming, S. P., . . . Malina, R. M. (2012). Urban-rural contrasts in fitness, physical activity, and sedentary behaviour in adolescents. Health Promot Int. doi: 10.1093/heapro/das054

8. Omigbodun, O. O., Adediran, K. I., Akinyemi, J. O., Omigbodun, A. O., Adedokun, B. O., \& Esan, O. (2010). Gender and rural-urban differences in the nutritional status of in-school adolescents in south-western Nigeria. J Biosoc Sci, 42(5), 653676. doi: $10.1017 / \mathrm{S} 0021932010000234$

9. Park, E. (2011). Overestimation and underestimation: adolescents' weight perception in comparison to BMI-based weight status and how it varies across socio-demographic factors. $J$ Sch Health, 81(2), 57-64. doi: 10.1111/j.17461561.2010.00561.x

10. Tai-Seale, T., Chandler, C. (2003). Nutrition and overweight concerns in rural areas: A literature review Rural Healthy People 2010: A Companion Document to Healthy People 2010 (Vol. 2013, pp. 115-130). College Station, Texas: The Texas A\&M University System Health Science Center, School of Rural Public Health, Southwest Rural Health Research Center. : Southwest Rural Health Research Center.

11. WHO. (2007). Growth Reference 5-19 years. Retrieved 03/10, 2013, from http://www.who. int/growthref/who2007 bmi for age/en/index. html\#

12. WHO growth reference for children and adolescents. (2008). Field Exchange(32), 1. 